\title{
Analysis of Soils Parameters in Correlation with Vegetation Period
}

\author{
ANISOARA-ARLEZIANA NEAGU, ALINA SOCEANU*, SEMAGHIUL BIRGHILA
}

University Ovidius from Constanta, Faculty of Applied Sciences and Engineering, Department of Chemistry and Chemical Engineering, 124 Mamaia Blvd, 900527, Constanta, Romania

Abstract: Soil is a complex ecosystem whose functionality is related to the links that exist between chemical, physical, biological parameters and microbial communities. Our purpose was to carry out an analysis of variance of chemical properties of the soil in relation to the vegetation period. The analysis of the soil gives us knowledge about the fertility status of the soil, which is closely related to the nutritional status of plants. The analysis involved urban soil, agricultural soil and greenhouse soil from Dobrogea area. Soil samples come from the urban area: Constanta, agricultural area: Ciocarlia de Sus and greenhouse:Cumpana. To estimate the seasonal changes in the soil, three periods were studied: before vegetation (sowing), after the vegetation period (harvesting), relative rest period (winter). The chemical parameters evaluated were: soil reaction $\mathrm{pH}$ (acidity degree), conductivity - as an indicator of the nutrients available in the soil (soluble salts), ion exchange capacity (cations and anions), organic matter (humus), nitrogen content (total nitrogen and nitrites), the amount of extractable iron. The $p H$ values were in the range corresponding to the weak acid-neutral soil for all three types of sample soils, with slight variations from one period to another while the recorded conductivity values indicate that the analyzed soils belong to the category of non-saline soils. The analyzed soil samples presented low concentrations of nitrites and the assimilable iron content was in the range $48.81-259.12$ ppm.

Keywords: urban soil, agricultural soil, greenhouse soil, chemical properties, vegetation period

\section{Introduction}

In the last years, the scientific community has focused on soil research because there is a direct link between soil health to obtaining healthy food [1-3]. The soil is the living covering of the earth that stretches on the layer of rock below and makes life on earth possible. Like air and water, the soil is part of the system that sustains our lives. The soil also plays a crucial role in providing food. The soil is the main means of production in agriculture, which allows the achievement of large, safe, and stable crops [4-5]. The soil structure is one of the key factors of soil and environmental quality because a healthy soil is necessary to sustain the development of vegetation and natural successional processes. Chemical soil parameters and appropriate supply of nutrients are very important factors for normal plant growth and development. A comprehensive assessment of the chemical properties of soils is important for explaining the relationship between basic soil processes and in monitoring changes in the soil environment [6].

The fertility of the soil depends on the humus content and its quality, so the cernoziomico soils have an average content of 4-6\% humus, being the richest, while the degraded soils have diminished concentrations of humus [7]. Nitrates and nitrites are substances widely used in soil fertilization, which increases the amount of nitrogen in the soil, nutrients and implicitly in food of animal origin. Nitrites are naturally present in soil, water, all plant matter, but also in food [8-11]. It can be found in small quantities and in polluted air. In cultivated soils and in water, their concentration may increase through the use of chemical fertilizers based on nitrogen, to which are added metabolites eliminated by other sources. The nitrites content of plants depends on the species, the genetic and environmental factors, as well as the agricultural exploitation processes. Iron is considered the fourth element to spread in the earth's crust. Iron ions reach the soil from residues and come in the form of flakes.

\footnotetext{
*email: asoceanu@univ-ovidius.ro
} 
The moisture and oxidation-reduction reactions that take place, but also the decrease of the $p \mathrm{H}$ of the soil, leads to the passage of iron in soluble form. The soluble iron is in the form of bicarbonates or metalorganic complexes, and in this form it penetrates into the groundwater, causing the concentration of iron in the water sources to increase [12-14].

The agricultural soil and greenhouse soil are used for conventional agriculture, realizing direct sowing, the land being without mechanical works of maintenance and weed control. The urban soil represents a variety of soil strongly differentiated structurally and morphologically, integrated within a locality, and strongly affected by anthropogenic activities.

Many researchers have been analyzed the properties of the soil because there are essential to maintain ecosystem function and protect land from degradation. Studies often shows that some parameters are variable and influenced by soil management options, as for example, $p \mathrm{H}$ with $\mathrm{Ca}, \mathrm{Mg}$ and other bases, and with Al saturation or clay contents, in tropical forest or savanna soils [15,16]. Soil quality indicators should be selected according to the management practices and the environment under study [17]. Management practices, such as crop rotation and tillage, have short-term and long-term effects on physical, chemical and biological properties of the soil [18].

According to our knowledge, there are few data on the chemical properties of the soils in different vegetation periods.

The aim of this study was to carried out an analysis of variance of chemical properties of the soil in relation to the vegetation period. The analysis involved urban soil, agricultural soil and greenhouse soil from Dobrogea area (Figure 1). To estimate the seasonal changes in the soil, three stages were studied: before vegetation (sowing), after the vegetation period (harvesting), relative rest period (winter). The parameters evaluated were: soil reaction $p \mathrm{H}$ (acidity degree), conductivity - as an indicator of the nutrients available in the soil (soluble salts), ion exchange capacity (cations and anions), organic matter (humus), nitrogen content (total nitrogen and nitrites), and the amount of extractable iron.

\section{Experimental part}

\section{Materials and methods}

The study was conducted in the south-east part of Romania, Dobrogea area. Dobrogea, situated between the Danube and the Black Sea has an arid climate, with high average temperatures $\left(10-11^{\circ} \mathrm{C}\right)$, high summer temperatures $\left(22-23^{\circ} \mathrm{C}\right)$, low rainfall (around $400 \mathrm{~mm} /$ year), tropical days and frequent droughts.

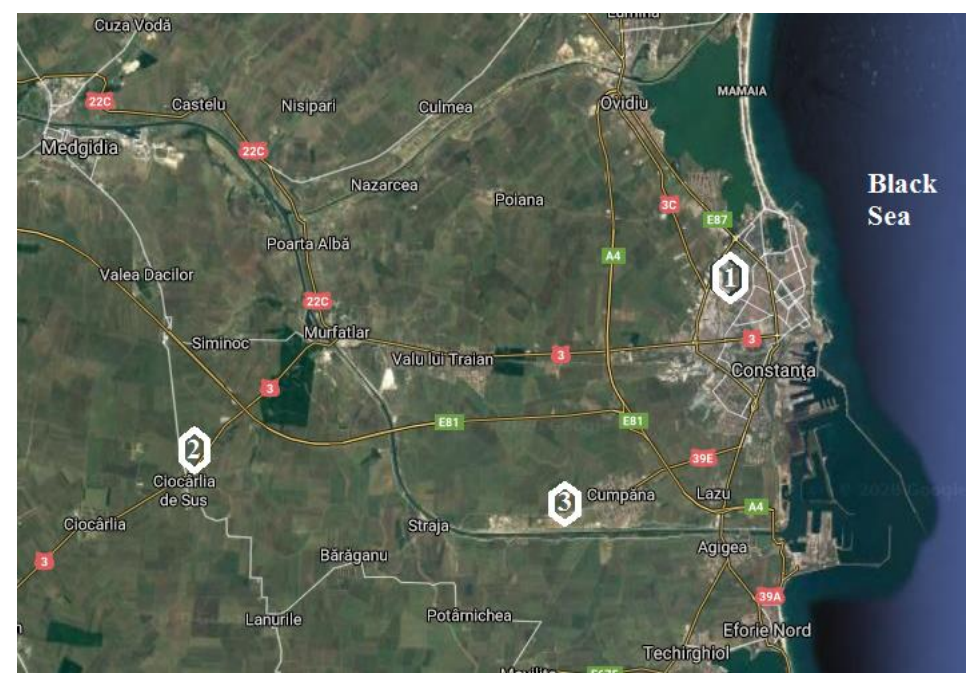

Figure 1. Sampling points: 1 - urban Constanta,

2 - agricultural Ciocarlia de Sus, 3 - greenhouse Cumpana 
For the sampling of soil samples, the barrel was used, obtaining an oblique wall pit and a vertical one. The samples were taken from depths between 0 and $60 \mathrm{~cm}$, at temperatures not exceeding 10 degrees Celsius. Soil samples for nitrogen content analysis were taken separately.

The soil samples were prepared by drying them at room temperature. For this purpose, the samples were spread separately on paper, in layers of about $2 \mathrm{~cm}$. They were left for 5 days, mixing from time to time. The bigger pieces were crushed with a clean hand. After drying, the samples were wet and screened through a $2 \mathrm{~mm}$ mesh screen.

In the case of the nitrogen content, the determinations were made from fresh soil samples, respectively at the humidity of the harvest, in order not to allow changes of concentration due to the microbial transformations that would take place during the storage.

\section{1. $p H$ determination}

$10 \mathrm{~g}$ of soil were weighted into the plastic beaker and $25 \mathrm{~mL}$ distillated water is added. The soil was left in contact with water for one hour, after which the suspension was stirred continuously for 3-5 min using a magnetic stirrer. The $\mathrm{pH}$ meter electrode was inserted into the resulting suspension and the $p \mathrm{H}$ of the sample was read.

\subsection{Determination of conductivity}

Electrical conductivity is a very fast, simple and inexpensive method to check soil health. While $p \mathrm{H}$ is a good indicator of the balance of nutrients available in the soil, the electrical conductivity indicates the amount of nutrients available in the soil.

The aqueous extract is the extract obtained by filtration of a soil-water mixture in which the ratio between the mass in grams of the soil sample and the volume of water added in $\mathrm{mL}$ is $1: 5$.

$10 \mathrm{~g}$ of the sample were weighted and pass it quantitatively into a $100 \mathrm{~mL}$ conical flask, where 50 $\mathrm{mL}$ of distilled water were added. The soil-water mixture was stirred for $15 \mathrm{~min}$ and the mixture was filtered through a glass funnel with qualitative filter paper. The first portions (about $5 \mathrm{~mL}$ ) of the filtrate are discarded. The vessel with the aqueous extract thus obtained was stirred for homogenization and covered until the measurement was made.

The total soluble salts content of the aqueous extract is calculated by the formula:

The total soluble salts content of the aqueous extract $=a \cdot F \mathrm{mg} / 100 \mathrm{~g}$ soil

a - the electrical conductivity of the analyzed aqueous extract $(\mu \mathrm{S} / \mathrm{cm})$

$\mathrm{F}$ - factor whose value is 3.4 for values of conductivity lower than $3000 \mu \mathrm{S} / \mathrm{cm}$ and 3.5 for values of electrical conductivity between $3000-6000 \mu \mathrm{S} / \mathrm{cm}$.

\subsection{Titrimetric determination of some anions and cations in soil solution}

$20 \mathrm{~g}$ of soil were weighted and passed through a $2 \mathrm{~mm}$ sieve into a $200 \mathrm{~mL}$ vessel where $100 \mathrm{~mL}$ of distilled water were added. The suspension was stirred for $15 \mathrm{~min}$ and was filtered on qualitative filter paper. From the solution obtained, aliquots have been taken with the pipette quoted to determine carbonates, bicarbonates, calcium and magnesium.

\subsubsection{Determination of carbonates}

The carbonate anion in the soil solution comes from the dissociation of the alkali metal carbonates. The quantitative determination is based on the titration of carbonates with sulfuric acid solution, in the presence of a mixed indicator, up to a $p \mathrm{H}$ of 8.3. The number of carbonate equivalents in the sample will be double the acid equivalents used in the titration, because the titration is carried out until the carbonates are converted into bicarbonates and not until they are completely neutralized.

The titration to indicator of the aqueous extract of the soil actually determines the total alkalinity of the aqueous extract, alkalinity which results predominantly from the hydrolysis of the alkaline 
carbonates. Other salts with alkaline hydrolysis, such as phosphates, borates, sodium silicate, salts which may be present in some soil types contribute to this alkalinity.

The carbonic anion content is expressed in mg per $100 \mathrm{~g}$ soil and is calculated by the formula:

$$
\mathrm{CO}_{3}^{-2}=\frac{2 \cdot V_{1} \cdot F \cdot N \cdot r \cdot 100}{m} \cdot 30 \quad\left[\frac{\mathrm{mg} \text { carbonate }}{100 \mathrm{~g} \text { soil }}\right]
$$

V1 - volume of sulfuric acid $0.01 \mathrm{~N},(\mathrm{~mL})$;

$\mathrm{F}$ - the sulfuric acid solution factor;

$\mathrm{N}$ - normality of the sulfuric acid solution;

$\mathrm{r}$ - the ratio between the volume of the extract obtained and the part used in the titratio;

30 - the gram equivalent for the carbonate ion, $(\mathrm{g})$;

$\mathrm{m}$ - mass of soil sample taken, $(\mathrm{g})$.

\subsubsection{Determination of bicarbonates}

The determination of the bicarbonate anion was made by titration with sulfuric acid and the alkalinity was resulted from the hydrolysis of the existing bicarbonates in the extract, up to carbonic acid.

The bicarbonate content is expressed in mg per $100 \mathrm{~g}$ soil and is calculated with the formula:

$$
\mathrm{HCO}_{3}^{-}=\frac{\left(V_{2}-V_{1}\right) \cdot F \cdot N \cdot r \cdot 100}{m} \cdot 61 \quad\left[\frac{\text { mg bicarbonate }}{100 \mathrm{~g} \mathrm{soil}}\right]
$$

$\mathrm{V}_{1}-0.01 \mathrm{~N}$ sulfuric acid volume, $(\mathrm{mL})$;

$\mathrm{V}_{2}$ - volume of $0.01 \mathrm{~N}$ sulfuric acid, $(\mathrm{mL})$;

$\mathrm{F}$ - the sulfuric acid solution factor;

$\mathrm{N}$ - normality of the sulfuric acid solution;

$\mathrm{r}$ - the ratio between the volume of the extract obtained and the part used in the titration;

61 - the gram equivalent for the bicarbonate ions, $(\mathrm{g})$;

m- mass of soil, $(\mathrm{g})$.

\subsubsection{Determination of calcium}

Calcium from the solution was determined quantitatively titrimetrically using a solution of EDTA at $p \mathrm{H} \mathrm{12-13}$ in the presence of murexid.

The calcium ion content is expressed in $\mathrm{mg}$ per $100 \mathrm{~g}$ of soil and is calculated by the formula:

$$
\mathrm{Ca}^{2+}=\frac{V_{1} \cdot F \cdot N \cdot r \cdot 100}{m} \cdot 20,04 \quad\left[\frac{m g}{100 \mathrm{~g} \mathrm{soil}}\right]
$$

V1- the volume of EDTA used in the titration of the test, $(\mathrm{mL})$;

F - EDTA solution factor;

$\mathrm{N}$ - normality of the EDTA solution;

$\mathrm{r}$ - the ratio between the volume of the extract obtained and the part used in the titration;

20.04 - the gram equivalent for calcium io, $(\mathrm{g})$;

$\mathrm{m}$ - mass of soil sample, $(\mathrm{g})$.

\subsubsection{Determination of magnesium}

The magnesium content of soils varies between $0.05 \%$ (sandy soils) and $0.5 \%$ (clay soils). Most of the magnesium in soils is contained in primary minerals (biotite, serpentine) and secondary minerals (chlorite, vermiculite, illite). In some soils, which contain alkaline-earth carbonates, $\mathrm{Mg}$ is also present as dolomite. 
For titration of magnesium ions from the soil solution, the mixture of calcium and magnesium ions with EDTA solution was titrated to alkaline $p \mathrm{H}$ (provided by ammonium chloride ammonium buffer) in the presence of eriochrome $T$. The concentration of magnesium ions was calculated from the difference between the volume of the EDTA solution used to titrate the mixture of calcium and magnesium ions and the volume used to titrate the calcium ion.

$10 \mathrm{~mL}$ of the soil solution were pipetted into a $100 \mathrm{~mL}$ flask and $7.5 \mathrm{~mL}$ of ammonia buffer and eriochrome $\mathrm{T}$ were added. EDTA solution was used to titrate solution.

The content of magnesium ions was expressed in mg per $100 \mathrm{~g}$ of soil and was calculated with the formula:

$$
M g^{2+}=\frac{\left(V_{T}-V_{1}\right) \cdot F \cdot N \cdot r \cdot 100}{m} \cdot 12.16 \quad\left[\frac{m g}{100 g \text { soil }}\right]
$$

$\mathrm{V}_{1}$ - volume of EDTA used in calcium titration, $(\mathrm{mL})$;

$\mathrm{V}_{\mathrm{T}}$ - volume of EDTA used in sample titration, $(\mathrm{mL})$;

$\mathrm{F}$ - the factor of EDTA solution;

$\mathrm{N}$ - normality of EDTA solution;

$\mathrm{r}$ - the ratio between the volume of the extract obtained and the part used in the titration;

12.16 - the gram equivalent for magnesium ion, $(\mathrm{g})$;

$\mathrm{m}$ - mass of soil sample, $(\mathrm{g})$.

\subsection{Titrimetric determination of soil humus by Walklei and Black method}

The most widely used method for determining soil humus is the quantitative determination of organic carbon, based on the oxidation of the organic substance in the soil. By applying the Walklei and the Black method humus was determined by oxidizing the organic substance in the soil with potassium bichromate in the presence of concentrated sulfuric acid and titrating the excess of potassium bichromate with the Mohr salt solution.

The humus content was expressed in percentages and was calculated with the relation:

$$
\text { Humus }=\frac{\left(V_{1}-V_{2}\right) \cdot 0.001036}{m} \cdot 1.16 \cdot 100 \quad[\%]
$$

where:

$\mathrm{V}_{1}$ - volume of $0.2 \mathrm{~N}$ Mohr salt solution used to titrate the control sample, $(\mathrm{mL})$;

$\mathrm{V}_{2}$ - volume of $0.2 \mathrm{~N}$ Mohr salt solution used for trituration of the potassium bichromate excess in the sample to be analyzed $(\mathrm{mL})$;

$\mathrm{m}$ - mass of soil sample taken in analysis, $(\mathrm{g})$;

0.001036 - the amount of humus that is oxidized by $1 \mathrm{~mL}$ of $0.2 \mathrm{~N}$ potassium chromate solution (equivalent to $1 \mathrm{~mL}$ of $0.2 \mathrm{~N}$ Mohr salt solution), (g);

1.16 - correction factor in relation to the percentage of carbon recovery $(100 / 86)$;

100 - percentage reporting factor.

\subsection{Determination of total nitrogen from soil by Kjeldahl method}

The method consists in the mineralization of the soil with concentrated sulfuric acid, when the nitrogen from the organic combinations is released and passed as ammonium sulfate. In reaction with a strong base releases ammonia which is removed from the solution by distillation and captured in an excess solution of $0.1 \mathrm{~N}$ sulfuric acid. The total nitrogen content was determined using the Kjeldahl system consisting of the Turbosog and Vapodens apparatus.

The percentage nitrogen content was calculated as follows:

$$
N \%=\frac{\left(V_{1} \cdot f_{1}-V_{2} \cdot f_{2}\right) \cdot 0.0014 \cdot 100}{m}
$$


$\mathrm{V}_{1}$ - volume of $0.1 \mathrm{n}$ sulfuric acid in which ammonia was taken, $(\mathrm{mL})$;

$\mathrm{f}_{1}-$ sulfuric acid factor $0.1 \mathrm{n}$;

$\mathrm{V}_{2}$ - volume of $0.1 \mathrm{n}$ sodium hydroxide, $(\mathrm{mL})$;

$\mathrm{f}_{2}$ - the factor of sodium hydroxide solution;

0.0014 - factor for transforming the volume of $0.1 \mathrm{n}$ sulfuric acid into grams of nitrogen;

100 - for percentage reporting;

$\mathrm{m}$ - soil sample analyzed, (g).

\subsection{Determination of nitrites from soil solution}

Nitrites extraction from the samples was performed with hot water followed by filtration. Nitrites were determined by reaction with the Griess reagent resulting in a red-pink azoderivative whose absorbance is directly proportional to the nitrites concentration.

$10 \mathrm{~g}$ of soil samples are ground and homogenized, then $80 \mathrm{~mL}$ of hot distilled water were added to the sample. The sample was stirred from time to time and after $30 \mathrm{~min}$, was filtered on filter paper with small pores into a $100 \mathrm{~mL}$ volumetric flask and completed with distilled water.

$5 \mathrm{~mL}$ working solution of nitrites and $5 \mathrm{~mL}$ Griess reagent were added in $50 \mathrm{~mL}$ volumetric flask. In parallel, the control sample was prepared in the same way, but instead of the nitrite solution, distilled water was used. After 15 min for color stabilization, distilled water was made up to the mark.

For the calibration curve (Figure 2) volumes of standard working solution (1, 3, 5, 10, 15 and 20 $\mathrm{mL}$ ), were introduced into $50 \mathrm{~mL}$ graduated flasks so that the concentration in the nitrogen to range from 0.04 to $0.8 \mathrm{mg} / \mathrm{L}$. The absorbance has been performed against the control sample at the wavelength of $520 \mathrm{~nm}$, with the DR 3200 spectrometer.

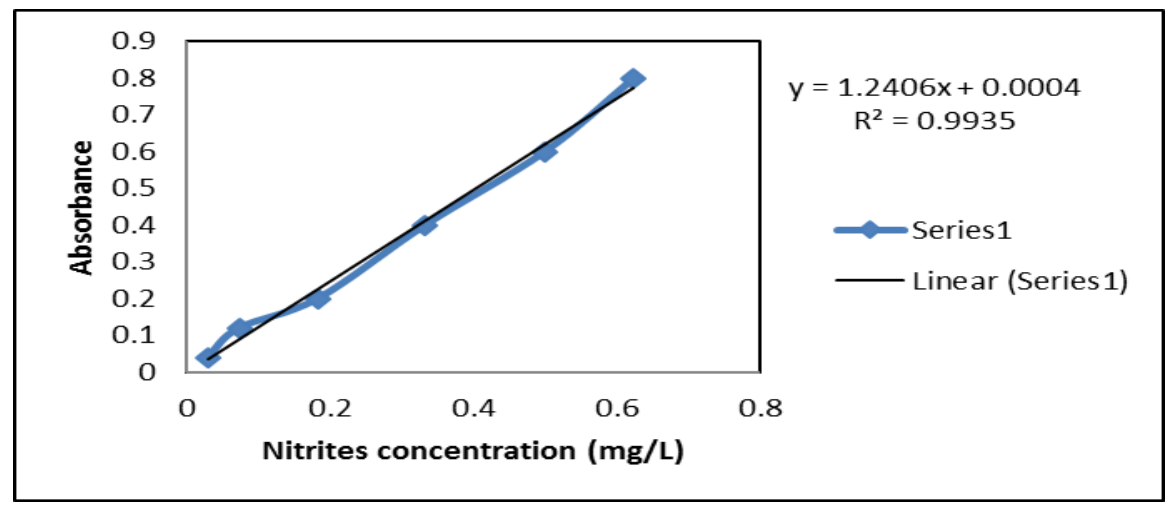

Figure 2. Calibration curve for nitrites determination

The nitrites concentration was calculated with the formulas:

$$
\begin{array}{ll}
C_{1}=\frac{1000 \cdot b}{m}\left(\frac{\mathrm{mg} \text { nitrites }}{\text { kg sample }}\right) \\
b=\frac{V \cdot a}{V_{1}} & (\mathrm{mg}) \\
a=\frac{50 \cdot c}{1000} & (\mathrm{mg})
\end{array}
$$

$\mathrm{c}$ - concentration of the sample, read on the spectrometer, $(\mathrm{mg} / \mathrm{L})$;

$\mathrm{m}$ - mass of the sample, $(\mathrm{g})$;

$\mathrm{V}_{1}$ - volume of sample solution used for spectrometric determination, $(\mathrm{mL})$;

$\mathrm{V}$ - total volume of sample solution, $(\mathrm{mL})$.

\subsection{Determination of the total iron accessible from the soil in ammonium oxalate solution}

The determination of the total iron accessible from the soil used method is based on the extraction of exchangeable iron from the adsorbent complex with $0.2 \mathrm{~N}$ ammonium oxalate solution which forms a soluble complex. Soluble and exchangeable iron from soil solution can be both bi and trivalent. The 
trivalent iron is reduced with ascorbic acid to Fe (II) and then the total iron is quantitatively determined colorimetric with orthophenatroline with which $\mathrm{Fe}^{2+}$ forms a red chelated complex.

In a $200 \mathrm{~mL}$ Berzelius beaker, $1 \mathrm{~g}$ of soil was weighted and $125 \mathrm{~mL}$ of $0.2 \mathrm{~N}$ ammonium oxalate solution were added and stired for $2 \mathrm{~h}$ on a magnetic stirrer. The slurry was filtered through fine-pored filter paper. $10 \mathrm{~mL}$ of the obtained extract with $1 \mathrm{~mL}$ of $2 \%$ ascorbic acid and $1 \mathrm{~mL}$ of $2 \%$ orthophenanthroline were added in $50 \mathrm{~mL}$ graduated flask. It was homogenized by stirring and left for one hour for color development. The absorbance of the solution obtained at the wavelength $515 \mathrm{~nm}$ against distilled water was measured on the DR 3200 spectrometer. In parallel, a control sample was prepared, introducing into a $50 \mathrm{~mL}$ graduated flask, $10 \mathrm{~mL} 0.2 \mathrm{~N}$ ammonium oxalate, $1 \mathrm{~mL} 2 \%$ ascorbic acid and $1 \mathrm{~mL} 2 \%$ orthophenanthroline. It was homogenized by stirring and left for one hour for color development, after which the absorbance and implicitly the iron concentration in the control sample were measured.

To obtain the calibration curve (Figure 3), in seven $50 \mathrm{~mL}$ flasks, volumes of standard solution B $(5 \mu \mathrm{g} \mathrm{Fe} / \mathrm{mL}$ ) were exactly measured so that the iron concentration was between $0.5-10 \mathrm{mg} / \mathrm{L}$ (the amount of iron introduced is between $2.5-5 \mu \mathrm{g}$ ). The standard working solution volumes were $0.5,1$, $2,4,6,8$, and $10 \mathrm{~mL}$. To each flask was added: $\mathrm{V}$ mL working iron solution, (10-V) $\mathrm{mL} 0.2 \mathrm{~N}$ ammonium oxalate, $1 \mathrm{~mL} 2 \%$ ascorbic acid solution, $1 \mathrm{~mL} 2 \%$ orthophenanthroline solution. After 15 min for color stabilization, distilled water was added to the mark and mix. The absorbance of the samples was read after one hour from their preparation.

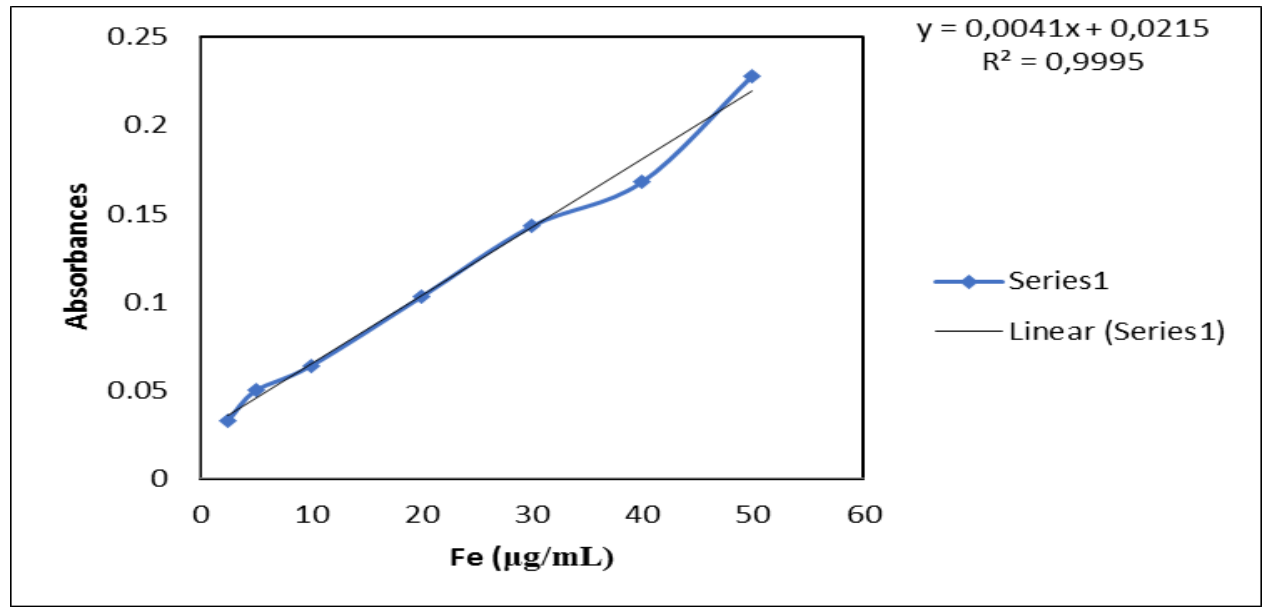

Figure 3. Calibration curve for iron determination

The iron extracted in $0.2 \mathrm{~N}$ ammonium oxalate solution is expressed in ppm ( $\mathrm{mg} / \mathrm{kg})$ and calculated according to the formula:

$$
F e=\left(F e_{p}-F e_{m}\right) \cdot \frac{r}{m}[p p m]
$$

$\mathrm{Fe}_{\mathrm{p}}$ - the amount of iron determined in the quota of the extract taken for measurement, $(\mu \mathrm{g})$;

$\mathrm{Fe}_{\mathrm{m}}$ - the amount of iron determined in the control sample, $(\mu \mathrm{g})$;

$r$ - the ratio between the volume of solution with which the soil was extracted and the volume of the quota part of the extract in which the iron was determined (125/10);

$\mathrm{m}$ - soil mass taken for extraction, (g).

\section{Results and discussions}

In Table 1 results about $p \mathrm{H}$, conductivity, soluble salts content, anions and cations content are presented. 
Table 1. Results about $p \mathrm{H}$, conductivity, soluble salts content, anions and cations content

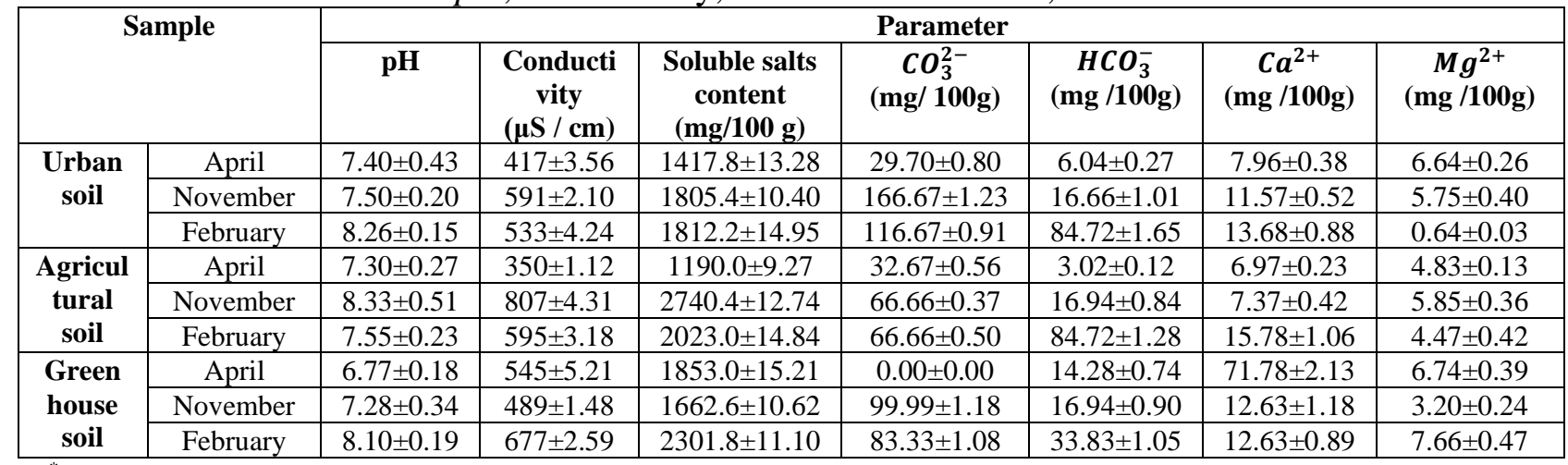

values are reported as means \pm standard deviation (SD) from triplicate determinations.

Soil $p \mathrm{H}$ is one of the most important properties of the soil, being applied for the general characterization of soils. The predominant reaction is neutral-weak alkaline, with $p \mathrm{H}$ values between 6.77 and 8.33. These reactions are generated by the presence of carbonates and soluble salts. In the investigated soils, the distribution of the Fe contents appears as a natural one, its quantity depends on the alkaline reaction and the calcium carbonate content.

Soil $p \mathrm{H}$ affects the content of minerals and nutrients needed for plant growth. Before a nutrient can be used by a plant, it must be dissolved in the soil solution. Most plants prefer slightly acidic to neutral soil with a $p \mathrm{H}$ of 6 to 7 , as this is the range in which all nutrients are available. Soil $p \mathrm{H}$ also affects the activity of soil microorganisms. Bacteria that break down organic matter are prevented in strongly acidic soils. This prevents organic matter from breaking down and binding to nutrients, especially nitrogen. Highly acidic or alkaline soils can increase the solubility of certain nutrients and minerals to the point where they become toxic to plants. For example, in very alkaline soils, calcium and magnesium levels are so high that they impede the availability of phosphorus.

Of the experimental values obtained for $p \mathrm{H}$, those in the range 6.8-7.2 indicate a neutral soil, those in the range 7.2-7.8 indicate a weak alkaline soil and those in the range 7.8-8, 5 indicates an alkaline soil. According to other studies, our experimental $p \mathrm{H}$ values are close to these [1-4, 19, 20].

The highest $p \mathrm{H}$ value (8.33) was obtained for agricultural soil, taken in November before vegetation, indicating an alkaline soil. The lowest value (6.77) was recorded for greenhouse soil, taken in April, indicating a weak acid soil. The study shows that the $p \mathrm{H}$ was kept in the range corresponding to the weak acid-neutral soil for all three types of sample soils, with slight variations from one period to another.

According to Sassman and Lee [21], soil $p \mathrm{H}$ is an important factor affecting sorption of pollutants to soils while the study of Palma et al. [22] show that $p \mathrm{H}$ could affect the sorption kinetic of acidic herbicides in volcanic soil. Soil $p \mathrm{H}$ data obtained by Domínguez-Haydara et al. [23] ranged from 7.5 to 8.2 , with relatively high nutrient contents are in accordance with our $p \mathrm{H}$ results.

The values of the recorded conductivities indicate that the analyzed soils fall into the category of non-saline soil types, having values less than $1700 \mu \mathrm{S} / \mathrm{cm}$. All nutrients important for plant growth have the form of cations or anions determining the level of electrical conductivity of the soil and the amount of nutrients that the plants can absorb. Scientific studies $[9,13,20]$ show that a high value of electrical conductivity, leads to the need for a smaller quantity of fertilizers but a greater amount of pesticides for weed control. In the case of the analyzed samples, the highest value of the conductivity $(807 \mu \mathrm{S} / \mathrm{cm})$ was obtained for agricultural soil, taken in November before the vegetation. A high value of electrical conductivity may indicate the presence of excess nitrogen fertilizers or a high level of sodium ions.

The values of the concentrations of the soluble salts from the analyzed samples were in the range: $1190-2740.4 \mathrm{ppm}$. According to the obtained results, the analyzed soils are strongly alkaline in terms of anionic content, with values ranging from $0-166.67 \mathrm{mg} / 100 \mathrm{~g}$ soil for the carbonate concentration. The obtained values can be a cause of the chemical and biochemical reactions that take place at the soil level, as well as the sources of water and vegetation existing on the soil surface. As regards the cation 
content, soils are generally characterized by low values of calcium and magnesium ions. The values obtained indicate the existence of the accessible form under which these ions are found in the soil solution. The factor that most influences total cation exchange capacity is the quantity of organic matter from the soil [2]. Several studies have reported that the most of natural soils are highly heterogeneous in terms of physico-chemical properties mainly including the adsorption phases (clay, organic matter and metal oxyhydroxides), cation exchange capacity (CEC) and soil $p \mathrm{H}$ [24].

In Figure $4 \mathrm{a}$ and $4 \mathrm{~b}$ results about humus, total nitrogen, nitrates and total iron content are presented.

(a)

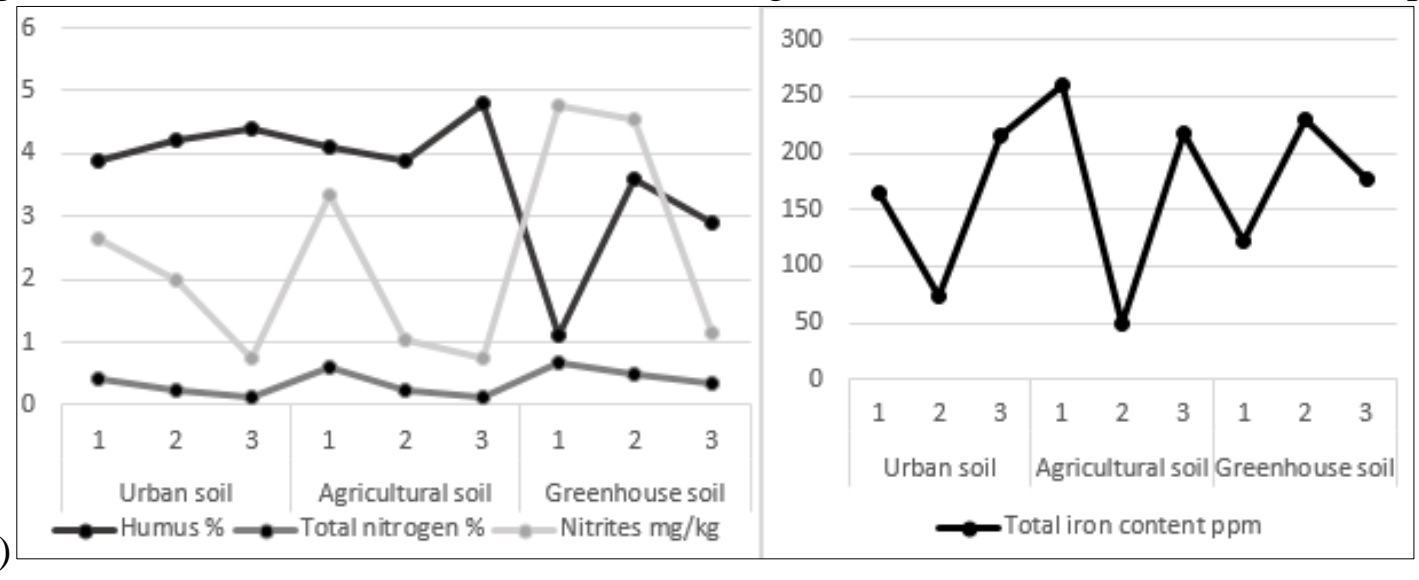

Figure 4. Results about humus, total nitrogen, nitrates and total iron content 1-April; 2- November; 3- February

The agricultural soils had a medium organic composition. The urban soil presented a very low organic composition before the vegetation period, reaching medium values during the vegetation period and lower values during the relative rest period, the values are in agreement with other studies [10]. A possible explanation of the observed differences may be the use of fertilizers on agricultural soils compared to urban ones. Another possible cause would be crop rotation, which is more common in rural areas. In the urban environment, one possible cause is atmospheric pollution that can influence soil activity. $p \mathrm{H}$ is the major controlling factor for chemodenitrification in soils, while $\mathrm{NO}_{2}{ }^{-}$concentrations, temperature and soil water content have been identified as additional controllers [25]. The humus content of soils from another studies [26] ranged from 1.46 to $2.41 \%$, as assigned to soil agronomic categories or from 5 to $12 \%$ for Suceava soils [4] and from 0.73 to $2.73 \%$ for Caras-Severin county soils [3].

The values obtained for the total nitrogen content show a constant decrease for all the analyzed soils, which shows the plants' use of the total nitrogen as a basic nutrient. The total nitrogen content was in the range $0.12-0.67 \%$, in agreement with TN content from some others studies [1,6]. Soils with total nitrogen values between 0.1 and 0.14 are characterized by low nitrogen content, those with values in the range 0.14- 0.27 are characterized by an average total nitrogen content and those with values in the range 0.27 0.6 shows a high total nitrogen content. Our results were similar with the nitrogen content in urban soils [10] that varies from 0.21 to $0.38 \%$ in the upper $10 \mathrm{~cm}$ with the highest values in the humus rich surface horizons. Soil N content was high in the Dobrogea area according to other study [11], where total nitrogen $(\%)$ content ranged from 0.03 to $0.12 \%$.

The highest nitrites content was obtained for the greenhouse soil in the sample taken in April (4.76 $\mathrm{mg} / \mathrm{kg}$ ). For all studied samples, a decrease in the nitrites content was observed from April to December. The analyzed soil samples show low concentrations of nitrites that can reach the soil as a result of the use of chemical fertilizers based on nitrates/nitrites to which are added metabolites eliminated by other sources.

The analyzed soils are characterized by poorly acidic or neutral $p \mathrm{H}$ values which makes the iron fraction easily assimilable to present average values, as a state of supply. The lowest values of the easily assimilable iron are found in the period after the vegetation period. The assimilable iron content from the soil was in the range $48.81-259.12 \mathrm{ppm}$, values in concordance with others studies [6,26,27]. The content of iron from Poland soils was between 6.58-32.77 ppm, lower than our results [6]. 
The relationship between chemical characteristics in soil samples was investigated using Pearson correlation at $95 \%$ confidence level. The results obtained indicate that there were many correlations (positive, negative, weak) between the studied parameters (Table 2). Generally, positive correlations were observed between $p \mathrm{H}$ and carbonates, total soluble salts and exchangeable minerals. Thus, $p \mathrm{H}$ values showed moderate correlations with $\mathrm{CO}_{3}{ }^{2-}$ ions (agricultural and greenhouse soils), soluble salts (greenhouse soil) and exchangeable iron (agricultural soil); weak correlations with total soluble salts (urban soil) and exchangeable iron (greenhouse soil); and very weak correlation with $\mathrm{Ca}^{2+}$ cation (urban and green house soils). In contrast, exchangeable iron and $\mathrm{Ca}^{2+}$ cation (urban soil) have negative correlations. Chemical parameters (such as $p \mathrm{H}, \mathrm{OC}, \mathrm{OM}, \mathrm{TC}, \mathrm{TN}$ ) did not positively correlate with the microbiological activity for Poland studied soils [6].

Table 2. Pearson's correlation coefficient of $p \mathrm{H}$ with carbonates, total soluble salts and exchangeable minerals

\begin{tabular}{|c|c|c|c|c|}
\hline \multirow{2}{*}{ Sample } & \multicolumn{2}{|c|}{ Parameter } & \multicolumn{2}{|c|}{$\begin{array}{c}\text { Exchangeable } \\
\text { iron }\end{array}$} \\
\cline { 2 - 5 } & $\mathrm{CO}_{3}{ }^{2-}$ & Total soluble salts & $\mathrm{Ca}^{2+}$ & -0.879 \\
\hline $\mathrm{pH}$ (Urban soil) & 0.069 & 0.387 & -0.675 & 0.487 \\
\hline $\mathrm{pH}$ (Agricultural soil) & 0.403 & 0.844 & 0.711 & 0.219 \\
\hline $\mathrm{pH}$ (Greenhouse soil) & 0.518 & 0.548 & 0.089 & \\
\hline
\end{tabular}

Humus (organic matter) is one of the main indicators of fertility, being the main source of nitrogen assurance of plants. The coefficient values from Table 3 showed humus content in various soil sample (urban, agricultural and greenhouse), had significant negative correlation cu their total nitrogen and nitrites content. The variation in the nature of correlation they have are due to the differences in the amount of organic matter and soil fertilizer.

Table 3. Pearson's correlation coefficient of humus content with total nitrogen and nitrites

\begin{tabular}{|c|c|c|}
\hline \multirow{2}{*}{ Sample } & \multicolumn{2}{|c|}{ Parameter } \\
\cline { 2 - 3 } & Total nitrogen & Nitrates \\
\hline Humus (Urban soil) & -0.794 & -0.926 \\
\hline Humus (Agricultural soil) & -0.219 & -0.152 \\
\hline Humus (Green house soil) & -0.552 & -0.083 \\
\hline
\end{tabular}

\section{Conclusions}

For plant growth, the soil provides many chemical elements necessary for development vegetation and crop formation. Soils contain different nature reserves of nutrients depending on nature parental material and soil type.

The chemical properties of soil are critical indicators for soil health assessment. The highest $\mathrm{pH}$ value (8.33) was obtained for agricultural soil, taken in November before vegetation, indicating an alkaline soil while the lowest value (6.77) was recorded for greenhouse soil, taken in April, indicating a weak acid soil. The analyzed soils are strongly alkaline in terms of anionic content and low values of calcium and magnesium ions. The urban soil presented a very low concentration of humus content before the vegetation period, reaching medium values during the vegetation period and lower values during the relative rest period. The nitrites values were in concordance with the total nitrogen content of the analyzed samples. The highest nitrites content was obtained for the greenhouse soil in the sample taken in April (4.76 mg/kg) and for all studied samples, a decrease in the nitrites content was observed from April to December. The variation in mean values of investigated parameters and the nature of correlation they have are due to the differences in type of soil and period of soil investigation.All these determinations that led to the evaluation of the nutrient content of the soil have that endpoint, on the one hand, establishing the need for mineral and organic fertilizers, on the other hand the continuation of conventional agriculture.

The results concluded that total organic carbon, cation exchange capacity and electrical conductivity are the most important indicators, which can be used to monitor soil functions and soil quality. 


\section{References}

1.CRISAN, V. E., DINCA, L. C., Rev. Chim. 71(2), 2020, p. 267.

2.CRISAN, V. E., DINCA, L. C., Deca, S. S., Rev. Chim. 71(4), 2020, 81.

3.NITA, L., TARAU, D., NITA, S., HEGHES, A., BERTICI, R., DICU, D., Rev. Chim. 70(7), 2019, 2463.

4.STANILA, A.-L., Rev. Chim. 70(3), 2019, 909.

5.SAMUEL, A. D., BUNGAU, S., TIT, D. M., MELINTE (FRUNZULICA), C. E., PURZA, L., BADEA, G. E., Rev. Chim. 69(10), 2018, 2608

6.FURTAK, K., GRAZDZIEL, J., GALAZKA, A., NIEDWICKI, J., Sustainability, 11, 2019, p. 3929

7.KOCHIIERU, M., FEIZIENE, D., FEIZA, V., VOLUNGEVICIUS, J., VELYKIS, A., SLEPETIENE, A., DEVEIKYTE, A., SEIBUTIS, V., Soil \&Tillage Research, 203, 2020, p.

8.PRISA, D., International Journal of Current Multidisciplinary Studies, 5, 2, 2019, p. 968.

9.BAI, X., GAO, J., WANG, S., CAI, H., CHEN, Z., Agriculture, Ecosystems and Environment, 288, 2020, p.1.

10.GORBOV, S. N., BEZUGLOVA, O. S., Euroasian Soil Science, 47, 8, 2014, p. 792.

11.HOSSAIN, N., MUNHIBBULLAH, M., MD. BARKAT ALI, K., HOSSAN MOLLA, M., Journal of Agricultural Sciences, 7, 10, 2015, p. 166.

12.TANG, J., WANG, W., YANG, L., CAO, C., LI, X., Science of the Total Environment, 688, 2019, p.622.

13.ZHU, W.X., CARREIRO, M. M., Soil Biology \& Biochemistry, 36, 2004, p. 279.

14.ZHANG, B., QINGMIN PAN, R.B., ZHAO, M., HAO, X., Geoderma, 346, 2019, p.75.

15.MENSAH, P. J., MARAKE, M. V., MUGABE, F. T., MAPESHOANE, B. E., NKHELOANE, T., MOLETE, S.F., International Journal of Current Research, 11(3), 2019, p. 2318.

16.HOU, X., HAN, H., TIGABU, M., CAI, L., MENG, F., LIU, A., XIANGQING M. A, China ecological Engineering, 138, 2019, p.171.

17.SCHEBERL, L., SCHARENBROCH, B.C., WERNER, L.P., PRATER, J.R., FITE, K.L., Urban Forestry \& Urban Greening, 38, 2019, p.267.

18.SOKOLOWSKI, A.C., PRACK MCCORMICK, B., DE GRAZIA, J., WOLSKI, J.E., RODRÍGUEZ, H.A., RODRÍGUEZ-FRERS, E.P., GAGEY, M.C., DEBELIS, S.P., PALADINO, I.R., BARRIOS, M.B., International Soil and Water Conservation Research, 8, 2020, p.185.

19.LIPIEC, J., USOWICZ, B., Science of the Total Environment, 633, 2018, p.1579.

20.GAVRILOAIEI, T., Rev. Chim. 63(4) 2012, 396.

21.SASSMAN, S., LEE, L., Environ. Sci. Technol., 39, 2005, p.7452.

22.PALMA, G., DEMANET, R. JORQUERA, M., MORA, M.L. BRICEÑO, G. VIOLANTE, A., Journal of Soil Science and Plant Nutrition, 15 (3), 2015, p.549.

23.DOMÍNGUEZ-HAYDARA, Y., VELÁSQUEZB, E., CARMONAA, J., LAVELLEC, P.,

CHAVEZD, L.F., JIMÉNEZE, J.J., Ecological Indicators, 103, 2019, p.182

24.MEDINETS, S., SKIBA, U., CRIEL, P., LOCK, K., EECKHOUT, H.V., OORTS, K., SMOLDERS, E., JANSSEN, C.R., Environ. Toxicol. Chem. 27, 2008, p.1748.

25.RENNENBERG, H., BUTTERBACH-BAHL, K., Soil Biology \& Biochemistry, 2014, p.1.

26.TKACZYK, P., BEDNAREK, W., DRESLER, S., KRYSZCZAK, J., BARANOWSKI, P., SLAWINSKI, C., Internationla Agrophysics, 31, 2017, p. 551

27.TUDOR, E., GRIGORE, A., DUMITRU, M., SIRBU, C., CIOROIANU, T., Scientific Papers, Agronomy, 56, 2, 2013, p. 153 (In Romanian)

$\overline{\text { Manuscript received: } 25.04 .2020}$ 